\title{
DE TOETOER TJILINAJA OP LOMBOK
}

\author{
DOOR
}

J. C. VAN EERDE.

Het hieronder volgende Sassaksche verhaal is overgeschreven van een lontargeschrift op 81 bladen, dat zich in de afdeelingsboekerij van Lombok bevindt en dat den roman bevat, die naar een der hoofdpersonen als Toetoer Tjilinaja wordt aangeduid.

Er komen verscheiden Balische uitdrukkingen en soms geheele Balische gedeelten in voor en bovendien vertoont ook het Sassaksch vele schrijffouten, die er op schijnen te wijzen, dat de overschrijver van dit exemplaar ongeletterd was en wellicht een Baliër is geweest, die het Sassaksch niet geheel meester was. Ofschoon dus dit geschrift voor de studie van het Sassaksch niet de waarde heeft van den Toetoer Monjèh (zie Bijdragen $7^{\mathrm{e}}$ Volgr. V blz. 17-109), is het toch ook op Lombok zeer bekend, en het neemt een vaste plaats in de inlandsche maatschappij in. Om die reden wordt het hier opgenomen, al vertoont ook dit verhaal van de liefde van Prins Pandji tot Prinses Tjilinaja onmiskenbare gemeenschappelijke gegevens met de Maleische Sjaïr Ken Tamboehan (zie H. C. Klinkert in Indische Gids 1881, I blz. 1165 e. v.) en met de Javaansche Angrèni (zie v. d. Tuuk Kawi-Balin. Wdbk i.v. daha en tjili). Het verdwijnen van de prinses, de droom van den prins, de terechtstelling en andere episoden van dezen roman herinneren sterk aan het verhaal van Ken Tamboehan, dat door Klinkert tot de oudere, vóór-Mohammedaansche literatuur wordt gerekend en volgens de Hollander in Palembang zou zijn opgesteld. Of aan onderlinge ontleening van de romans Tjilinaja en Ken Tamboehan moet worden gedacht dan wel aan een gemeenschappelijke afkomst, worde hier 
niet nagagaan, maar Balische vertalingen van dezen roman wijzen er wel op, dat het verhaal van Tjilinaja van Lombok zijn weg naar Bali heeft gevonden en dus niet voor Lombok een der vruchten van de Balische overheersching is geweest.

Tjilinaja is een troetelnaam van een prinses van Děhe, waarom deze roman ook onder den naam Toetoer Datoe Děȟ bekend is. In de nalatenschap van Dr. H. N. van der Tuuk zijn verschillende exemplaren van dit geschrift aangetroffen (zie Beschrijving Brandes I. blz. VII en 235); de aanhef van het daar vermelde handschrift $n^{\circ}$. 327 komt in hoofdzaak met het begin van het hieronder gedrukte geschrift overeen. Eene inhoudsopgave moge voorafgaan. 


\section{Inhoud van den Toetoer Tjilinaja.}

Metrum: Dangdang Goela.

De dichter groet de lezers en roept hunne toegeeflijkheid in. Hij heeft dit verhaal geschreven op Zondagavond de $28^{\text {ste }}$ van de maand Safar, van het Balische jaar IÇaka 1816. Er wordt mededeeling gedaan van de twee vorsten van Děhě en van Kěling, broeders, die geen kinderen bezaten. Zij kwamen overeen naar een kajangan te gaan om aan Batara Goeroe Sakti kroost te vragen. Met groot gevolg togen zij daarheen, en de vorst van Děȟ legde, nadat allen gebaad hadden, de gelofte af, dat hij de godheid twee karbouwen zoude offeren, zoo hij eene dochter verkreeg. Karbouwen met goud versierd, met kostbare kleeden behangen, de hoorns met goud en edelsteenen getooid en van zilveren hoeven voorzien. De vorst van Kěling legde de gelofte af, dat hij, mocht hem een zoon geboren worden, bij de kajangan zoude terugkeeren met "wat pinang, sirih en tabak» (offermaaltijd).

$\mathrm{Na}$ aldaar gegeten en sirih gekauwd te hebben, keerde men huiswaarts en na verloop van drie maanden werd het duidelijk, dat hun gebed verhoord was. Over de zwangerschap wordt verder niet gesproken. De vorsten waren zeer verheugd bij het aanschouwen van hunne gemalinnen en gaven feesten. De vorst van Děhě kreeg een zeer schoon dochtertje, die van Kěling een schoon jongetje; zij waren met de kinderen zeer in hun schik. Toen deze kinderen vlug konden loopen, zou men de gelofte aan de godheid volbrengen. De vorst van Këling bracht drie prachtig versierde karbouwen en ging met groot gevolg offeren na gebaad en van kleederen verwisseld te hebben, doch de vorst van Děhe kwam zijne gelofte niet na en had niets medegenomen dan eenige wilde bladeren als geschenk voor de godheid. Nadat men gegeten had zouden de vorsten vertrekken, doch er stak een windvlaag op en door Allah's wil ten opzichte van den vorst van Děhe, werd zijn dochtertje door den wind medegevoerd. De vorst en zijne gemalin stonden onthutst, terwijl hun kind hemelwaarts 
vloog en uit het gezicht verdween. De vorst van Děhě werd gek en geheel verward van zinnen.

Metrum: Pangkoer.

Men keerde naar huis terug en nu wordt over het verdwenen kind gesproken. Het kwam terecht in de Taman Sari, een tuin beheerd door Pé Bangkol ( de kinderlooze»), een onderdaan van den vorst van Këling. Deze man kwam uit zijn huis naar buiten en vond in den tuin het kleine schoone kindje; hij nam het op en bracht het aan zijne vrouw. Beiden waren met dit geschenk van den Allerhoogsten (jang Agoeng) zeer verheugd en baadden het, maakten op het voorhoofd van het kind een teeken met sirihspog en gaven het een kleedje, zoodat hare schoonheid uitkwam als de glans van een spiegel waarop het opkomend zonlicht valt. Het was een lust voor de oogen van het echtpaar. Niemand wist van hun bezit iets af en als er iemand kwam verborgen zij het kind gauw.

$\mathrm{Na} 15$ jaren droeg dit meisje reeds een haarwrong en toen kon zij al spinnen (was zij volwassen).

Op zekeren dag lag de prins van Keling met zijne gezellen Kalang en Wiroen te dutten onder een loodsje en droomde in zwaren slaap. Hij droomde, dat de maan op hem viel. Verschrikt werd hij wakker en richtte zich op. Ontsteld maakte hij zijne gezellen wakker en vroeg hun de beteekenis van den droom, doch zij wisten geen uitleg te geven. Den volgenden dag liet de prins door een volgeling van den droom mededeeling doen aan zijnen vader, die zeide: Als hij op jacht gaat, zal hij spoedig wild verkrijgen; als hij vogels gaat vangen, heeft hij stellig succes; als hij naar de zee gaat om te visschen, vangt hij stellig wat. De vorst verbood echter aan den prins de verklaring van den droom mede te déelen. Toch vertelde de volgeling een en ander aan Raden Pandji en diens dienaar I Togog Semar zeide: alaten wij dan gaan visschens. De volgeling Wiroen sprak: jiij schijnt trek in visch te hebben, laten wij liever doen, wat de prins wil.. Deze wenschte in den vroegen morgen boschkippen te gaan jagen. Leeftocht en strikken om boschkippen meê te vangen werden medegenomen en men ging op de vogelvangst in het bosch van 
Karang Loewar. Maar men zag geen enkele boschkip, ja, zelfs geen hagedis; negenmaal stelde men de strikken, doch men ving niets. Toen sprak de prins: "laten wij hier maar bij Pé Bibi Kili (zelfde als Pé Bangkol) blijven overnachten, dan kunnen wij het morgen nog eens probeeren». Zij kwamen aan den rand van het dorpje Bawas Aoer en hoorden het getik van een weverspoel. De prins sprak: "hoort eens wat een schoon geluid maakt die weverspoel.» Wiroen zeide: "gaat $U$ er maar alleen op af, misschien krijgt $U$ de weefster te zien». De prins ging en loerde ingespannen, doch zag niets, want zij zat achter een drievoudig gordijn; alleen haar glans scheen er doorheen. De deur in het huis van Pé Bangkol was met een dwarshout gesloten en de prins riep dat men hem zoude openen en toen Pé Bangkol aan dat bevel gehoor gaf verborg het meisje zich vlug in een groot aarden vat (voor het afwasschen van rijst bestemd).

Metrum: Sinom.

Pé Bangkol vroeg beleefd wat de prins tot hem voerde en deze zeide op de vogelvangst te zijn, verzoekende daar te mogen logeeren, wat dadelijk werd toegestaan. De prins vroeg: "aan wie behoort dat weefgetouw ?» waarop Pé Bangkol vlug antwoordde: "van wien zou het anders zijn dan van mij, ik heb weven geleerd. " Doch de prins geloofde niet dat een man zulk een schoon weefsel kon maken waarom de vrouw van Pé Bangkol zeide dat zij de maakster ervan was. De prins en zijn gevolg aten daar en matten en kussens werden klaargelegd voor hun logies. Den volgenden morgen gingen zij weêr op de vogelvangst naar het bosch en beraadslaagden onder een boom, hoe zij haar te zien zouden krijgen, die door moeder Bibi Kili verborgen werd gehouden. Wiroen raadde aan dat de prins zich zeer nederig en zacht moest voordoen bij de echtelieden: "als water vermengd met bloemen en kapas. " Uit het bosch namen zij giftige gadoengwortels mede en vermengden die met drank (běrěm). Toen zij bij het huis terugkeerden verborg Ina ${ }^{5}$ Bangkol het meisje in den grooten pot; daarna diende zij den prins het eten voor. Deze zeide: »ik heb

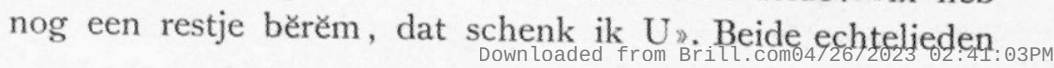


dronken ervan, en vielen beschonken neêr. Toen zochten de jongelieden overal naar het meisje, terwijl de prins bij het weefgetouw ging zittten. Toen hij ook meê ging zoeken bleef haar, dat uit den pot hing, aan zijn krisgevest haken. Hij onderzocht wie zijn kris vastpalkte, trok aan het haar, en daar kwam de maagd te voorschijn schoon als de volle maan. De prins zeide: "Sta op schoon meisje" doch zil viel in ommacht tegen hem aan, waarop hij haar allerle lieve woordjes toesprak. Doch zij bleef bewusteloos en daarop gelastte de prins aan Sewar water te brengen in een klapperdop; hil besprenkelde het gezicht wan het meisje, dat bijkwan. Ook het echtpaar ontwaakte wit de bedwelming. Het meisje zeide: "waram houdt $u$ mij vast op uw schoot, ik ben slechts we slavin en alleen max waardig wwe voetzolen te wasschen en veegster te zinn op wwerf. Moeder Banglool zeide: «waram houdt a mine dochter vast? Doch de prins gelastte haar te zwijgen, wijl zij hem om den tuin had trachten te leiden en hem niet de waarheid had verteld.

La Kentjili (de maagd) drukte hare verwondering uit, dat de prins blijken gaf van haar te houden, doch deze sprak: "mijne liefde voor $u$ is oprecht; zoo gij mijne ziel geen medicijn schenkt, word ik gek en krankzinnig». La Kentjili antwoordde: "dat kan ik niet, want ik ben geene passende partij voor $u$ ". "Mijne liefde voor $u$ is oprecht; moge de Heer ons voor immer vereenigen». "Hoe is het mogelijk, dat $U$, een vorstenzoon van mij kunt houden, want Uw vader zal zich tegen mij kanten en zoo zal ik $U$ in 't onheil storten". "Als dat slechts is, wat gij vreest, ik zal $u$ verdedigen tot in den dood; mijn hart is geheel met u vervuld". Het meisje hernam: "laat mij liever alleen». En de prins: "wat er ook gebeure, gij zult de mijne zijn voor altijd». Het meisje: "Als u die gelofte nimmer vergeet, ben ik de uwe».

Toen maakten zij een draagstoel en zij droegen haar naar het plein voor het paleis te Këling. Den volgenden morgen gaf de prins kennis aan den vorst van de mislukte vogelvangst en dat hij het meisje tot zich had genomen. De vorst ontstak in woede en weende: sdat zijn zoon zich in een vuil, stinkend water had gestort". Doch 
de prins zeide haar tot in den dood getrouw te zullen blijven.

La Tjilinaja (zoo wordt het meisje voortaan genoemd) vreest den toorn van den vorst en vraagt nog heen te mogen gaan, doch de prins zweert haar: "als gij in 't vuur geworpen wordt, verteert mijn lichaam tegelijk met het uwe tot asch». Toen dit aan den vorst werd overgebracht gelastte hij: »hij moet die vrouw van geringe afkomst wegdoen, want hij heeft eigen nichtjes te Singasari en te Gěgělang, laat hij daar een van kiezen of eene prinses van Djagaraga, doch deze keuze is niet goed».

Ondanks dit verbod liet de prins zich met La Tjilinaja in 't huwelijk verbinden, doch de vorst was hierover zeer vertoornd en schold op het meisje, terwijl hij verdriet had over het gedrag van zijn eenigen zoon.

Metrum: Dangdang.

Pandji bleef veel van zijne vrouw houden, die na negen maanden van een schoonen zoon beviel; Pandji was dol van vreugde, zoodat hij eigenhandig de nageboorte begroef; hij zelf haalde brandhout om het gebruikelijke vuur te stoken en zelf haalde hij badwater. Zeer veel hield hij van zijn zoon en hij droeg het kind maar altijd door, baadde het en gaf het te eten; steeds verzorgde hij het kind.

De vorst, een en ander vernemende, wendde ziekte voor, liet zijn zoon bij zich roepen en zond den prins uit om medicijn te zoeken, zeggende dat volgens de deskundigen hij alleen die machtig kon worden. De medicijn, zonder welke de vorst niet zou kunnen genezen, was het hart van een wit hert.

De prins ging met gevolg naar het woud om op het witte hert met strikken en netten te jagen. Men ving vele herten, doch geen wit dier.

Onderwijl liet den vorst zijn pěpatih bij zich komen met den beul (djoeroe towèk) en gelastte La Tjilinaja te dooden; "want anders zou Pandji zeker ongelukkig worden, wijl hij aan niets anders denkt dan aan die vrouw». "Neem mijn kris, genaamd Boeboeng Rěbas en dood haar, doch niet het kind». De pěpatih ging met de kris naar Tjilinaja, die juist haar kind van zes maanden oud op de schoot 
had. Hij zeide gezonden te zijn om haar te dooden. $\mathrm{Z}_{\mathrm{ij}}$ antwoordde: "tegen dat bevel zal ik mij niet verzetten, maar ik verzoek eerst mijn kind te mogen zoogen; wie zal het doen, als ik dood ben?»Dat werd toegestaan en zij zoogde haar kind. "Verzadig u mijn kindje, want ik zal spoedig sterven, en dan blijft gij alleen achter.» Toen gelastte de pĕpatih haar mede te gaan, doch zij verzocht eerst haar kind nog te mogen baden: "want ik zal mijn kind in deze wereld niet meer bij mij hebben.» De pěpatih gelastte haar voort te maken en zij baadde haar kind. Daarna ging men op weg, de pépatih voorop, de vrouw in het midden, dan volgde de beul. $\mathrm{Z}_{\mathrm{ij}}$ had haar kind in den slendang en sprak lieve woordjes tot hem: "ik houd zoo veel van u, knaapje, maar kan u geen liefde weer bewijzen».

Op het veld buiten de stad, waar zij gedood zoude worden, aangekomen sprak de pĕpatih: "sta recht op, want hier zal je gedood worden.» $\mathrm{Zij}_{\mathrm{ij}}$ vroeg: »mag het op een verlaten plek gebeuren, waar geen menschen komen? Want als gij mij hier doodt zoo dicht bij de stad, zal de lijklucht binnen het paleis dringen; het is beter op een meer verwijderde plek, op de Lěndang Mĕnangis (veld van het geween)».

De Pexpatih stond dat toe en men ging op weg naar een afgelegen landtong. Langzaam ging de tocht verder, terwijl zij lieve woordjes tot haar kind sprak. "Gij zijt als een djamboevrucht en ik zou je willen inslikken; waarom zijt gij tot mensch geworden, was maar liever bloed en water gebleven, opdat ik niet niet aan dit leven hechtte, want nu, mijn hartje moet ik van je scheiden. Nu je tot mensch zijt geworden heb ik verdriet; zuig maar flink, zoolang ik nog leef.» Toen zoog het kind en zij zoende het en zeide: "hoe zal het u gaan, als ik u alleen laat in deze wereld?» Men kwam op de landtong aan en ging onder een kětapangboom zitten, dicht bij een bilë-boom. De pĕpatih zeide: "sta op, want de beul zal je doorsteken, maar leg je kind eerst neêr.» Nog eenmaal vroeg zij uitstel om haar kind te zoogen, opdat het niet zou gaan huilen. Ook dat werd toegestaan en zij zoogde en zoende het kind, zeggende: „blijf hier zoet mijn kind en schrei niet te veel van verdriet omdat ik je hier alleen laat, en wordt een gehoorzaam mensch. 
Daarna legde zij op last van den pěpatih haar kind neer en het zoenende zeide zij: "hier is een bilěvrucht; speel er meê, want ik verlaat je.» Toen stond zij op en sprak: "Raden pěpatih, let op mijn bloed; is het rood dan is het een teeken, dat ik eene slavin was van lage afkomst; mijn bloed is dan rood en stinkend en het valt ter aarde. Doch ten teeken, dat ik van hooge afkomst ben, zal mijn bloed ten hemel spuiten en het is wit en welriekend. Let goed op, als ik word doorstoken.» Toen kwam de beul te voorschijn met de vorstelijke kris en de pěpatih zweeg. De vrouw stond met de armen over de borst en sprak de geloofsbelijdenis uit; de beul stak haar in de borst en er spoot wit bloed uit, dat zeer welriekend was en het spoot ten hemel. Zij was dood en lag daar neer als een slapende; de pěpatih dekte haar met kětapangbladeren toe en men ging heen, het lijk daar achterlatende. Onderweg zeide de beul tot den peppatih: "die wij gedood hebben, was een voornaam persoon.» Voortgaande viel de hand van den beul af; hij werd blind; hij struikelde over een boomstam, zoodat hij neus en kin wondde; hij kroop verder en viel dood in een ravijn. De pěpatih deed verslag van het gebeurde aan den vorst en deze stond sprakeloos van verbazing.

Ondertusschen had de op jacht zijnde Pandji een boozen droom; hij droomde dat de edelsteen in zijn ring brak. Verschrikt werd hij wakker, keerde vlug naar de stad terug en hoorde daar wat er gebeurd was. Hij begaf zich toen naar de landtong en vond daar het kind in de zonnehitte liggen schreien en zuigende aan het lijk van zijne moeder. Pandji viel neder van ontzetting, doch nam spoedig zijn zoontje in zijnen armẹn als was hij eene vrouw; en hij vatte het hoofd van het lijk en zoende het. "Had ik maar geweten, dat ik door een list der menschen op jacht was gezonden, dan ware ik niet gegaan en had u niet verlaten.»

Ondertusschen kwamen de jachtgenooten van Raden Pandji daar ook bij het lijk en allen weenden en waren gek van verdriet. Een hunner stelde voor om het lijk te wasschen en te begraven, doch Pandji wilde dat niet. "Laat zij in mijne armen tot stof vergaan». Zeven dagen zat hij daar met het lijk, toen zeide een stem uit den 
hemel: "als gij werkelijk uwe vrouw zoo vurig bemint, zal ik u een raad geven».

Metrum: Sěmarandan ě.

"Maak vlug een kist en leg haar daarin; bindt er een lang touw aan en werp de kist in zee; laat het touw niet los en zorg er voor niet aan de zuidkant ervan te komen, dan zal het leven terugkeeren». Hij deed, wat de stem zeide. Nadat hij het rotantouw eenigen tijd had vastgehouden, brak het en tot schrik van Raden Pandji dreef de kist weg. Nog honderd dagen liep hij langs het strand en als zijn kind honger kreeg, voedde hij het met plantenspruiten en hij gaf het den naam Megat Sih (voor wien de moederliefde heeft opgehouden»). Hij maakte zich daar een hutje en wachtte maar op Gods beschikking of de kist niet weder door de golven zoude worden aangespoeld. Terwijl hij daar in afzondering leefde, kwam de vorst van Deȟ met muziek en groot gevolg van gewapenden om in zee te baden. Men zag de kist doch als men die wilde grijpen, dreef deze verder de zee in; maar toen de vorst zelf in zee ging, kwam de kist naderbij en een witte vogel vloog er uit. De vorst greep de kist en toen trok men die op het strand en opende die. Er lag een vrouw-mensch in, dat zeide: "mijn vorst, ontferm $U$ over $m i j$ ". De vorst nam haar er uit en zette haar op een draagstoel, zeer verheugd een zoo schoone maagd gevonden te hebben. "Het is, prinses, alsof ik uit den grooten oceaan een stuk goud heb gekregen, ik neem $U$ aan als mijne dochter».

Met veel luister en muziek, werd zij door een groot gevolg omstuwd naar het paleis gedragen en er werd een groot feest gevierd ter eere van de pas gevonden dochter. Dat feest duurde verscheiden dagen en ieder werd onthaald,

Ondertusschen verbleef Pandji met zijne gezellen aan het strand en het kind werd al verstandig, droeg al een kleedje en kon al loopen. De gezellen heetten: Semar, Togok, Djoeroedé en Kalang. Toen het kind de gamelans hoorde, vroeg het aan zijn vader wat die muziek beduidḑe, en deze antwoordde dat de vorst een feest gaf. Het kind vroeg toen er heen te mogen gaan, doch de vader hield hem daarvan terug, daar hij zoude uitgelachen worden om 
zijne armoedige kleederen. Megarsih (= Megat Sih) begon te schreien en ten laatste ging hij, door den volgeling Wiroen gedragen, naar het feest te Děhě. Deze volgeling bleef onder een heg verstopt, wijl hij geen passende kleêren had om op het feest te verschijnen en het kind ging alleen naar den kring der toeschouwers. Er stond daar ook een dienstmaagd van de pas aangekomen prinses, en zij wees hare gezellinnen op het schoone kindje. "Breng hem naar het paleis en laat hem aan de prinses zien». Zij nam het jongetje bij de hand en bracht het bij de prinses. Toen deze hem zag, herkende zij haar kind, nam hem op en zoende hem. Zij weende en verborg haar gezicht in haar kleedje; zij gaf hem te eten, liefkoosde, baadde en kleedde hem met prachtige kleederen, zoodat ieder hem bewonderde. Bovendien gaf zij hem kleederen mede voor zijnen vader en droeg hem op dezen te zeggen den volgenden dag het feest te komen bijwonen. Het kind bracht de kleederen en de boodschap over en de vader besloot naar het paleis te Děhě te gaan. Met blijden intocht en gevolgd door ieder, die zijn schoon uiterlijk zag, kwam hij de stad Děhě binnen, en betrad het hofplein als een hooge gast door den pěpatih begroet, die hem naam en woonplaats vroeg. "Ik kom uit het gebergte en ben een zwerveling zonder onderdaks. Aan de prinses werd kennis gegeven, dat de schoone Pandji en het mooie kind waren aangekomen.

Een wederzijdsche herkenning en blij wederzien had plaats; de vorst van Děhě nam den prins van Kěling als zijn schoonzoon aan. Ook de vorst van Kèling kwam er bij en na eene algeheele onthulling der feiten in tegenwoordigheid van al de vorsten uit den omtrek, werd een verzoenings- en offerfeest gevierd, zooals in het slot in Dangdangmetrum wordt beschreven. 


\section{Toetoer Tjilinaja.}

Dangdang goela.

Bismillah ịrachim: Tabés ingsoen amoerwahing sègènding gagoeritan têmbang dandang goela, minangkế salémor até, sangnè hini baoe patoet, djoemakane moenggoeh le toelis base Sasak rarampoetan, jen asala tandoek, patoetang pade sié tềbang si mematja djrah side pade sill si sastrakoe dét onját.

Myah dinangkoe sinenoelis, malem Senen malh oelan cyafr tanggal loelikwer taven bé, jen tjare Dali itoeng vine terngèn aranirekoe mijah tave loce nele Doekoet aranipoen lan rah enem tenggek toenggal.

Sigen lotjap genkoe panggong le bawon toelis tjaritan datoe Dehe. Mijah tyaritan datoe sî le Keling lan semalin pade "ndét dejang bidje sasanalk bangkol baé djarine loembar datoe, datoe Dehe loembaming Keling, bandjoeme besemaje gen apatoeh oedjoet balalangon le kajangan genne nede le letatara Goenoe Sakti adéne bedoené bidje.

Dehe djandì bandjoer loembar glis, datoe mijal pangiringne pade toeme ta-iring bandjoer si kavela laxan prenjai, ramé tace nine mame leka" nging datoe, djari "nde" kotjap let langan, kotjap dateng le $e^{z}$ Datara foeroe Sakti, bandjoeme pade mandjak.

Ndé ne soeve bandjoer pade mandir, datoe mijah pangiringno pade, nine mame pade rame, bandjoer bemanil datoe, datoe Dele njoegoel sésangi, mogangkoe latariman si Datara Goeroe, era" moen koe dejang anak, pone nine, koe keté njaoer sesangi, koe njambeli kao doewa. Toer kao'ne pade belkoelit si1 permas kalawan saklat, betangge ${ }^{\text {* }}$ mas bataretes, bakoepak

Dix 解x 
sělakě loeroet toer běléndong soetra sikoening; sakěno manik sangina lés Batara Goeroe sěsangin datoe lé'Děhě; bandjoer njamboet datoe Kéling běsěsangi, nané akoe djas děngan: pěnoenaskoe lés Batara Sakti, sang koe déjang anak po'ně mamé, éraskoe malik běkětés mandi sraoep diriskoe, poskoe djaoe $^{s}$ boewa ${ }^{s}$ sabiris, lékos garo salembar, mako sapanjoesoet, ngěno manik sěgangině, lés Batara, sěsangin datoe lés Kěling, datoe Děhě ramékyat. Ndésně soewé bandjoeran mandi datoe mijah pangiringně padě, nině mamě padě ramé, běsoekan mangan nginěm, djari oewah simangan $\mathrm{ai}^{s}$, bandjoerně padě mamas, oewah mamas, bandjoer padě oelés odjok désa, datoe mijah pangiringně bělés běris pade ramé lés langan. Djari éné tjaritan pangiring mijah datoe, 'ndes kotjap lés langan, kotjap oewah datěng lés gědeng, něng tjaritaně bandjoer tingkah datoe si oewah bësangi, oendakara soewěně sibalangon datoe, ara $^{5}$ wah tloe boelan bandjoer kotjap, datoeně padě běkisi, katariman pandaně. Djari ěněng tingkahně běrisi, kotjap gěněp, wah tloe boelaně, datoe liwat si $^{5}$ ně gégér, běsoekan soekan ngipoek, girang lalos gita sibini, sigěn njĕrěk bebidjě. Těpě kontés toetoer, djari wah kotjap babidjě, datoe Děhě bidjaně ně bandjoer bini kaliwat si'ně solah. Lan sěmalih datoe si lés Kěling wah babidjě laki liwat solah, bandjoerně běsoekan baé, djělo malěm bětětoeroet, ipoe kaoela si bělés běris, mapan liwat soekaně déjang bidjě bagoes, djari gělising tjarita bidjaně datoe oewah padě taho běrari bandjoerně padě loembar aning kajangan gěn něnjaoer sěsangi, datoe Děhě linjos lés sěmajě ěndésně isis sanggoepně laé lèkasně noebagalidoeng, dika datoe silés Kěling,

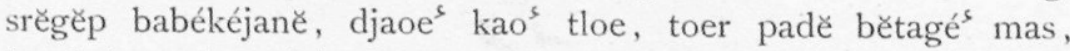
lan běkoepak, sělakě loeroep maoekir, baléndong soetrě abang. Pangiringně padě soekě taék singiring ijě; tingkah datoe loembar, bini laki padě ramé, toerně těngiring bandjoer $\mathrm{si}^{\text {s }}$ kaoela lawan prěnjaï, ramé taoé nině mamě, lèkas ngiring datoe; djari ndés kotjap lés langan, oewah datěng, lés kajangan bini laki, bandjoerně padě mandjak. Bandjoer ramé padě saling dědjit, siběsirěm datoe dait bidjaně bini laki padě ramé, djari wahně si adioes, padě taés lèkan $\mathrm{ai}^{\text {s, }}$ bandjoer běsalin bédang, ara soetrě dadoe, ara ${ }^{s}$ ně nganggo perrmas, datoe dait pangiringně blés běri' ramé besoekan soekan. Bandjoer nědë padě gělis' datoe Děhě nista běbékéjan, pade lalap poetjat baé, djari oewah nědě bandjoer datoe Děhě lan datoe Keling, datoeně ngagěn loembar, 
datěng angin bandjoer saking kasoeka ${ }^{5}$ Allah, lés datoe Děhě bandjoer takèlèp $\mathrm{si}^{\text {s }}$ angin, bidjaně datoe Děhě. Momomero datoe Děhě bini laki si njarěminang, bidjaně ngawang ${ }^{2}$, padě donga ${ }^{5}$ langit baé, djari ilang bětroes, 'ndéně baoe těgita malik, nènè bini siîlang, datoe gila bandjoer, saling oedjěl děngan pandjak, saling kětjak sangět sî́ně loepas diris, marě mangoendang santa.

Tembang Pangkoer.

Djari loembar datoe pade, odjo ${ }^{5}$ désě barěng děngan pangiring, něngkě tě pakonté toetoer djari ěněng tjaritaně; 'ndès ně kotjap tingkahně sigila datoe, kotjap bidjaně si ilang, oewah datěng lés Taman Sari.

Siépén kěbon kakěmbang, Pé Bangkol pandjak datoe lés Kěling; kotjap Pé Bangkolně soegoel, lèkan dalěm baléně bandjoer lèkas tamě lè kěbon bětroes bandjoeraně dait kanak bagoes lagoes masi běri. Glis mandjoer ngoemba ${ }^{s}$ ijè bandjoer oelés datěng lès Bangkol bini, Pé Bangkol sinině bandjoer kaliwat síně girang, déjang anak katariman si ${ }^{\text {s }}$ Yang Agoeng; bandjoeraně bait ai gantang, bandjoerně mandis ijĕ glis. Bandjoer po'na sémbè' boera ${ }^{5}$ kéréng kaïn gěnně si'nidjil kalěm kari, séré soegoel tjahjě bagoes tan péndah roewan kas-ně sitětémbak isi ${ }^{\text {s }}$ djělo běroes soegoel; Pé Bangkol sinině mamě liwat soekani ningali. Tingkahně si déjang anak, ndèsně ara taoe něnowés laïn, dimin aras datěng taoe sěbo'ně ijě gantjang, si toe datěng pasti moelě ndés ně taos; Pé Bangkol sinině mame kaliwat isisně kikip. Tepěkonté tjaritaně sating-kah-ně Pé Bangkol si wah dait, kotjap soewéně oewah ěmboen laèsně akoe $^{s}$ anak, sawatarě ara limaolas taoen, tkes něwah kapoesělan, oewah-ně tahoe migis njoekit. Těpěkonté tjaritaně, bandjoer bidjan datoe lè Kèling barěng si $^{s}$ Kalang lan Wiroen, 'miwah sasanakaně, padě barěng adjęp lè oeké djoeloe, oewahně padě kalělěpan, nènès laki bandjoer impi; impiněno katoesoenan isis boelan, bandjoerne wah ijě pasti, kaliwat isisně těkědjoet, bandjoerane bětroes mandjak lělělaki momot kěngěn ipi bandjoer, pos ně dodos Wiroen Kalaṇg, adoeh kakas akoe impi. Djari sělapoesně ngasě, adoeh kakas akoe tagèt $\mathrm{sị}^{5}$ impi, baja 
apě těmah impikoe, impingkoe ngiwa boelan, silas kaka $^{5}$ jènně lěngé jènně bagoes, těmahkoe singipi boelan djari njamboet padĕ glis. Doeh nénés kadji měmindah ndèsně baoe isi ${ }^{s}$ kadji těgěsin impi, bandjoerně běmanik aloes, lamoenně ngěno kakas, onja $a^{s}$ djęmas dě lalo tamě bělatoer, ito lés datoe mamis dě atoerang $\mathrm{si}^{s}$ koe ngimpi. Ndésně kotjap pětěng déš̌, kotjap běnar dèn těroeně lèkas gělis, sigěnně mamarěk lés datoe, 'ndésně kotjap lés langan, ijě datěng dèn Djoeroedé bandjoer matoer: měran kadji parěk lés Pěmban, sasamping njokor njěmbah gělis. Datoe tagèt njarěminang, sisně dateng dèn djoeroedé masi glis, bandjoerně běmanik datoe, baja apé kěno aras, lèmas lalos antě datěng něpět akoe, sang sameton mès ndés klar. Den Djoeroedé matoer gelis: "koela bělatoer lés Pěmban, bidjan Pemban ijě ngimpi roebin lais, impině boelaně toeroen, tibě lés bawo'n iwa'ně, no gawéng koela tamě bělatoer, le $\mathrm{e}^{s}$ bawas arěpan Pěmban, koela noenas těmah impi.»

Datoe no běmanik gantjang, lamoeně ngěno dja impině Loe' Boeling, derponě lěgra takoet, angěn těmah impině, moen sili koe moeně njerrěk gĕnně maoe ${ }^{s}$, jènně lakoewang měmikat, pasti gěnně olih paksi. Jénně gěněm aning sègarě, djalě djaboeng moelě pasti gěnně olih, no těmahně, lamoen ling koe, ijě singimpi oelan, oeli něka mès lalo bahé balatoer, éra soesah lalos ijě, Loes Boeling ngatijeng impi. Den Djoeroedé pamit gantjang, bandjoer oelés aning pakoedan gělis, ndésně soewé dateng bandjoer, Raden Pandji masi mandjak, dèn Djoeroedé bandjoerně gělis bělatoer, měran lamoen manik Pemban, sinjěta impin pengkadji. Jen pengkadji gěn měmikat, moelě pasti si péngkadji gěn oelih, mwah jèn péngkadji djaboeng; sipěnggawé ta oelah, moele pasti isi péngkadji gěn maoes, sakěno manikně Pemban, sinjêta impin péngkadji.

Djari aras tamanikně, lěle laki lés kadang kadijé sami, moeně ngěno manik datoe, atawě tělékas njĕran oetawi těmikat paksi. Djari njamboet Togok Sĕmar, moen ling kadji silas djaboeng mantjing, djari aras basan Wiroen, lamoen ling mèssimělas, djoeroe mati momodos ěmpa ${ }^{5}$ bilang laboe lamoen ling koe dja'ně někě, kagokas nénés alaki. Djari ara tamanikně, lělělaki léskadang kadijé sami, lamoen dě toeroet karěpkoe, tětamikat kěrěta, bandjoer djĕmas lagi kělěm ta betroes, mikat le $e^{s}$ Karang Loewar, malah ${ }^{2}$ sang ta olih. Djari njamboet sělapoesně, měran silas, sarě kajoen péngkadji, lělělaki manik aloes, nané 
tanjarě gěpang sangoe, sangoe $\mathrm{ai}^{\mathrm{s}}$ isi $^{\mathrm{s}} \mathrm{lopa}^{\mathrm{s}}$, mama $\mathrm{a}^{\mathrm{s}}$ ngoedoet srěgep bandjoer, bandjoer sělapoe'ně padě, sakajoen kadji jasiring.

Djari kotjap pětěng désě, bandjoer mara padě sargep tarik, sangoe $a^{\text {s }}$ mama ${ }^{5}$ ngoedoet, set sandět děngan kěrěta, djari kotjap wah tjawis sělapoes, ndésna kotjap pětěng désě, benar bandjoer padě tangi. Satangině bandjoer loembar, ngodjos gawah si gěn měmikat paksi, bandjoerně padě djaoes, krěta doewě pasang, bandjoer lékas ngodjos krěta siamboer, mëmikat le $e^{s}$ Karang Loewar sadatengně mëmasang glis. Sapasangan doewě pasangan, tedos lilis ndés aras apẽ moeni, kaling krëta gèn maǒ, kadal ngrésék nde ${ }^{5} \mathrm{ar}^{5}$, moelě pèdaitně tědos soewoeng, kanti jan sảwas pasangan, lai ${ }^{5}$ désanè si-sêpi. Djari ara" tamanikne, néné laki $l^{5}$ kadang kadijé sami silas lang kakas ta moendoer, kědoeng latjoer lalékan, éra ${ }^{5}$ djëma $^{5}$ ta malik oetoekang latjoer, $\mathrm{da}^{5}$ taoe $^{5}$ lés $^{5}$ aning désa, tanindos $l \mathrm{e}^{5}$ Pé Bibi Kili. Djari njamboet Wiroen Kalang, 'mran sila maras manik péngkadji, djari

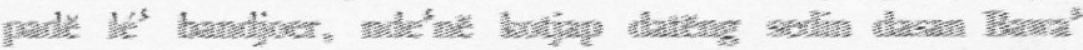

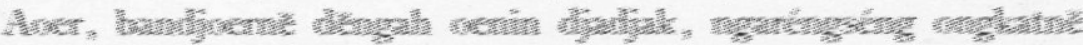

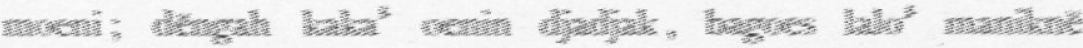

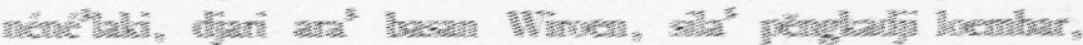

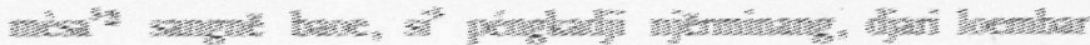

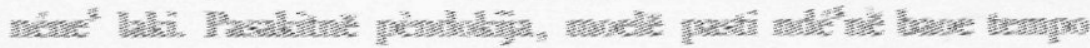

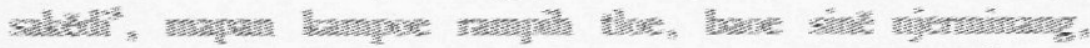

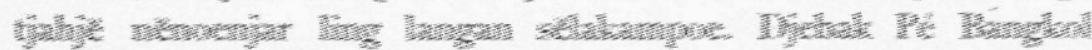

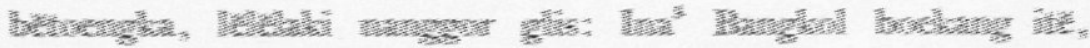

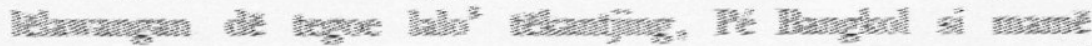

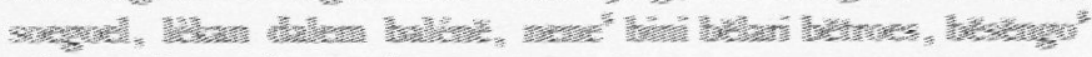

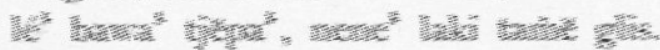

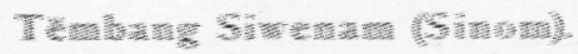

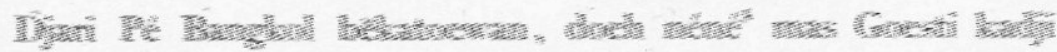

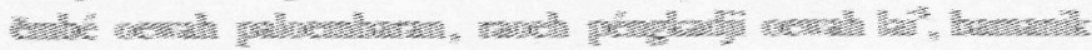

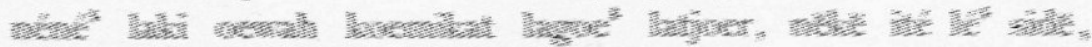

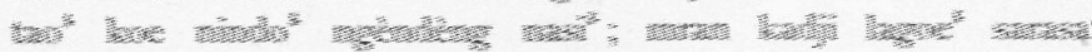

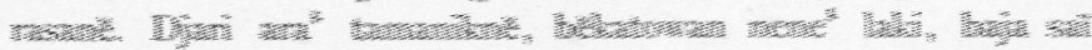

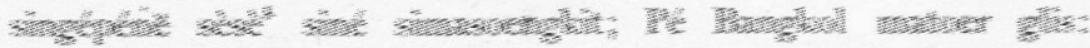


kadji sěné épén tenoen, sai ${ }^{5} \mathrm{si}^{5}$ gěn épéně, masa ara taoë lain, moele kadji beradjah njèsèk soetrě. Moele dès koe sadoe sidě, gěněpé sèsèkan sěni, mapan sèsèk papilijén, moela pasti ara lain, épéně sèsèk sini, pasti moelě dés koe sadoe, lagoe oewah těš̌bohin, Pé Bangkol nině baběling: kadji mindah moelě njèsèkijě. Moeně ngěno lingda inas, dikas akoe masi ini, da sargěpang nasi djangan, adés ta glis mangan maï, apan djĕma no malik, koemikat noetoekang latjoer, dakas ngěno sidjěma, 'nda sadangang akoe nasi, tengari no gěn koe kěté nepět sidě. Pé Bangkol sinině gantjang, isi andjegané glis, djari 'ndé ara soewéně, bandjoer něnjoegoelang pěsadji, tarěpin si néné laki, dait Kalang děngan Wiroen miwah sasanakně; bandjoer nědě padě glis, wahně nědě bandjoer pade ngoedoet mamas Bandjoer soegoel tipah galěng, parědjëpan néné laki, bareng si Wiroen lan Kalang, 'nda běgarinting, ěntjěpně néné laki, liwat lalos sině ladjoe, 'ndéně kotjap pětěng désa, běnar bandjoer padě tangi, satangi-n ${ }^{\mathrm{c}}$ malik loembar odjos gawah. Sadatěngně si lés gawah, datěng lěndang Togok Moeni: sila nèngkě tabatlah, $\mathrm{ao}^{5}$ manik néné laki, bandjoerně tokol djarik lés bawas kajoe si aloeng; bandjoerne běrarasan lé sanakně néné laki: kaka Wiroen ngoembé saranta madaja, pos ne baoë gěn pagitan, sasěbowan Bibi Kili, moela ara taoe solah, ito lé inas Bibi Kili; Wiroen balatoer glis: atoer kadji moeně patoet, barěng masi dja ija, sino isi tangěsorin tagahorang isi aï poetjokkapas. Patoet lalos lingdě kaka, ngěno manik néné laki, bandjoer léka Togok Sěmar métě poetjoek gadoeng glis, maoe djaoe ijĕ malik; padě ngenti poetjoek gadoeng, bandjoerně, telep ija lé běrěm si néné laki; djari kotjap wajan djělo panas lapar; loembar malik ngodjo désa, 'ndéně kotjap néné laki, kotjap Pé Bangkol sinině, glis njěbo néné bini, tamang naï ije glis lé dalem taropong baroe, poně sělět lé atas, taoně si milih njoekit; bandjoer kotjap néné laki loewar dasan. Tědo lilis ongkat djadjak, ndé ara ongkatně moeni, padě ngodjos djadjebakan, djébakně ndéně balěnting, nén'é laki tamě glis; Pé Bangkol simamě soegoel, kělékně sinině gantjang Ina Bangkol někě glis, isi arén néné laki mélé mandjak. Pé Bangkol sinině gantjang, isi arén glis $^{2}$, djari ndè ara soewéne bandjoerně soegoel pěsadji, ngarĕpin néné laki, děngan Kalang lawan Wiroen, miwah sasanakně, pade nědě glis ${ }^{2}$; wah nanědě bandjoer padě ngoedoet memamas 
Djari ara tamanikně lé Pé Bangkol néné laki Ina Bangkol mélé sidě běrěm salongkoe sakědik, 'ndéně boewè isi kami, dě iněm barěng amangkoe, Pé Bangkol nině girang, kělěkně simamě glis, éh Pé Bangkolně nginěm brěm païtja. Bandjoer naïněm ijě pade, 'ndéně soewé bandjoer ngoering, padě lěngah kampalěngan, nènè laki bandjoer glis barěng sasanakně padě métě dědarě sibagoes, ara tamě baléně, ara mondok bawa sambi, néné laki palar mandjak lè sèsèkan. Néné laki bandjoer oerěs, sigěn métě néné bini, bandjoerně lé léjot danganan, si boeloeně néné bini, boeloeně kari saï, ndéně boewé tamě boeboeng, sino ngaléjotinijě, landéan kris néné laki, bandjoer glis néné laki balik dang. Baja patangantoekije, kris koe sigenně těri, bandjoer glis balik dang, seloen boeloe ngaléjotin, bandjoer natoetijě glis, bandjoer soegoel dèdarě sibagoes, tjahjaně mara boelan, sěděkně poername sidi; kaka Wiroen menné pojě sipétantě. Wiroen bandjoer kěto gantjang, sělapoeně pade tarik, padð běnga sigěgita, si roewe bagoes toer manis, néné laki ngririh, doeh dén darě boewa boeloe, sila péngkadji ngasě, dasrěminang gama kadji, néné bini masi lépé le boniwa. Pasti moele nděně ngasě, néné bini harri ${ }^{2}$, masi lépé lé boniwa, sanget sinaloepa diri dakaně hari ${ }^{2}$, néné laki no ngaroemroem: doeh dén darě pangéran, dě srěminang awak kadji, sila ngasě doeh dendare maspangéran. Daka ngéno 'ndéně ngasě, néné bini sajan sěpi, dakaně hari², néné laki no ngaroemroem glis bandjoer datěng Sěmar, béntékaï wadjah djaï, bandjoerně srěwoepin, néné bini ngasě bandjoer, Pé Bangkol siwah lěngah, nině mamě padě tangi, satangině bandjoer belatoer njęmbah. Doeh goesti kadjï pangéran, ngoembé sěno néné laki, sangka si těgadingang, si kadji ta iwa, si batang péngkadji goesti, 'ndéně sěděng péngkadji; mapan péngkadjï no datoe, kadji moele toe pandjak, sěmaï péngore gading; pantěs kadji djari djoeroe njapoe léjah. Nimbal Pé Bangkol sinině, ngoembé séno néné laki, sangkg sina tëgadingang, anak anak kadji sisasěné, běmanik néné laki, nengkě djra padě loewé toetoer, sidě sina noengkoelang, někě djra da loewé ling, mapan sidě těkětoewan dé pasadja.

La Kéntjili malik ngoetjap, tetoemoen soekan péngkadji, lagoe émanang kadji, sangka péng kadji soekě, lé awak kadji mas goesti, bermanik néné laki, pasti moelang koe kadoedoet, isi sidě den darě, moen dèk sidě gěn ngowatin, moelě pasti 
boeroeng djogang pajoe gilě. La Kéntjili malik ngoetjap, moen ngěno soekan péng kadji, moelě gěn kadji měmindah, ndéně sěděng timpal péng kadji, běmanik néné laki, pasti moelang koe kadoedoet, isi sidě dén darě, moganara soekan widi, těbarondang lé doenija dateng ahérat. Sakěno djari manikně, néné laki lé La tjili, La Kéntjili malik ngoetjap, tětoe moen soekan péng kadji, lagoe émanang kadji, si mami peng kadji datoe, pědas siněndé soekě, lé awak kadji mas goesti; 'ndé kadji boeroeng gěn ngěmasin těmah sédě. Lamoen sino takoetang ně, no těmanik néné laki, telah mésa koe njandang ijē, jadijan koe těmah pati, dén koe boeroeng gěn daït, aténg koe no mapan ladjoe, kangěn sidě masmirah. La Kéntjili matoer glis, daka ngěno gěn kadji noenas měmindah. Néné laki malik ngoetjap: doeh pangeran néné goesti, djrapenda soesah mirah, manangkoe gěn těmah pati, ndé koe boeroeng, gěn baï La Kéntjili malik matoer: sok 'nda péngkadji loepas lé djandji péng kadji sěné, měran néné gěn kadji ngatoerang awak.

Djari ara tamanikně, lé sanakně Radén Pandji, Kaka Wiroen samědajě, ngoembé si tangrasanin. Wiroen belatoer glis: atoer kadji moela patoet, gěn kadji mijak djempaně; kna manik néné laki, bandjoer mijak djoeli no bandjoer pragat. Bandjoer mara taék gantjang, néné bini baön djoeli, bandjoer ngagęn Togok Sěmar, lémbar djoeli pade tjawis, néné laki memargi. Něngkě těpěkonté toetoer, 'ndéně kotjap lé langan, kotjap datěng désa Kling, sadatěngně bĕtroes tame lé pakoedan.

Djari ara tamanikně, lé sanakně néné laki, Kaka Wiroen selapoe da, ngoembé si tangrawosin; Wiroen belatoer glis: atoer kadji moele patoet, sila bandjoer si djema kadji oelé aning désě glis, taätoerang ito lé Datoe mamitě. Djari ara tamanikně, lé sanakně radén Pandji: Kaka Wiroen něngkě léka, atoerang lé datoe mami, tingkahkoe oewah bědaït, si adinď̌ Kaka Wiroen, jěn apě kasoekaně, adé glis dateng malik, dèn Djoeroedé pamit bandjoer oelé gantjang. 'Ndéně kotjap silé langan, kotjap datěng bandjoer nangkil, Datoe tagèt bakatoewan: apě ségawé mè glis, sang sametonmè 'ndé kělar. Dén Djoeroedé glis matoer, koela matoer oeningě, tingkah koela mikat paksi, latjoer koela kretě sopo ndénara. Simaoeně bidjan Pemban, dé pan ara anoe lain, ara anakoela Pěmban, ni Bibi Kili moe laés, sino minang kahoelih, tingkah koela mikat latjoer, toer wah datěng lé pakoedan, wah bědjangkěp 
néné laki, nèngkè ngoembé soekan Pemban koela noenas. Soegoel manik Datoe doekè, ngoembé kéhatén Loe Boeling, sangkanê timpoh awakné lé aî kotor sirèmis, mè badas ije glis, sangne ini ${ }^{\text {'s }}$ pati lingkoe, sa djra dija djra, nabait la Bibi Kili, 'ndénè tao moelé tjêtjèndeknè mèsas, lalo baé di mè gantjang. Den Djoeroedé pamit glis. Djari kotjap lé langan, kotjap datèng to lé Pandji, Wiroen bèlatoer glis: mran lamoen manik Datoe, sa djra dija djra, no tamanikne Mami péng kadji, Mami Pémban liwat lalos sine doeke. Radén Pandji bandjoer ngoetjap: "moela pasti dén koe ini", mana sadoeka-doekane, jadijan koe temah pati, den koe boeroeng gèn běroentoeng. La Tjilinaja ngoetjap: dénné salah atoer kadji, 'ndénara boeroengan kadji jas séde. Moen atoer kadji pangéran, gèn kadji noenas bèpamit, mapan Pèmban liwat doekě, dékadji boeroeng ngèmasin, ngèmanik néné laki, doeh pangéran sarin kasoer, djra 'nda soesah mirah, jén dé tětipoh lé api, akoe djoeloe djari awoe barèng sidé. Néné bini malik ngoetjak, moen ngěno soeka péngkadji, sok djra péngkadji loepas lé djandji péngkadji sěné, běmanik néné laki, pasti moele dè koe boeroeng, baroentoengan sidě Kaka Wiroen léka malik, dě atoerang lé Datoe akoe gěn nikah. Den Djoeroedé pamit léka, 'ndéně soewé bandjoer nangkil, bandjoerně bělatoer sěmbah, bidjan Pemban néné laki, děsidě gěn běbrěsih, pasti 'ndéně soeka noeroet, sigenn manik Pĕmban. Datoe no bermanik glis, kanggo ijě taoë 'ndéně patipengadjah. Jènně pati ling koe djaně, koerang senině lain, pisa sampoeně si mésas, sakarěpně koe pilénin, jèn si lé Singasari, Gagelang lan Singasantoen, jèn si lé Djagaragé,

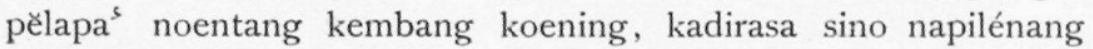
dirině. Lalo baé dimè gantjang, mè kawin ijě glis, kědoeng déně pěngadjah, 'ndé koe gěn běbali' ${ }^{\text {s }}$ malik. Den Djoeroedé bandjoer pamit, lékaně bandjoer bětroes, 'ndeně kotjap lé langan, kotjap dateng to lé Pandji, sadatengně bandjoerně bělatoer njembah. Samanik manik manikně, boewés atoerang lé Pandji, néné laki bandjoer ngoetjap: doeh kaka ngoembé dja isi, dě brěsin akoe glis. Den Djoeroedé bandjoer matoer: moen peng kadji gěn patoetang, djĕmak pengkadji bekawin, tjara gampang péng nikah simamě. 'Ndeně kotjap pětěng désě, benar bandjoerně běkawin, saking glising tjaritě, wah pragat sìně běkawin, Pé Bangkol pade malik, sinině mamě bětroes oelés aning balèně, djari 
ěněng néné laki, bandjoer kotjap mami’ně katoengkoel soesah. Manik lés dalěm bosang, baja ngoembé Radén Mantri, sangkanětimpoh awakně, lés ai kotor sirěmis, pědas sině 'ndé maoe lain, pasti moelě někě doedoet, isi lakokodjoran, pěsas opas pěsa ${ }^{s}$ tjětik, baja apě kès těmah Raden Mantri někě. Gojo si djěmas soeléně, wah nanéjang nganak sai, gěnně ïnget lés awakně, lagi někě loepas diris, baja ngoembé si koemikir, adé'ně pegat baroentoeng, jénně bélo oentoengně, Radén mantri si La Tjili, pasti boeroeng Loe Boeling djari manoesě.

Tembang Dandang.

Hěněng Datoe si soesah běpiker, kotjap Pandji sibini běbosang, néné laki soesoeka bahé, néné laki no bandjoer njadang sidoet njadang djadjaï, isis soekaně déjang bidjě, těpěkonté toetoer, kotjap soewéne běbosang, néné bini, oewah iję gěnç siwa sasih, parèkne gèn bẻbidje. Néné bini bandjoerne tẽdjandji nę bẻbidjè, jen kèlèm djoema'at néné laki liwat gégér, soegoel bidjané bagoes liwat solah makane laki, néné laki no girang déjang bidjè bagoes, kadoege endi'ně bětandikě, ngali" tanah, da sida koening bègading, sinalět adés kakas.

Mwah $\mathrm{si}^{\text {t }}$ baoe kajoe $\mathrm{ai}^{-5}$, lan babatang, djari padédéngan, néné laki loembar baé, kaliwat si'ne kadoedoet, lè bidjanè makatnè laki, endi'nè pègat bariwa, lan simandis dawoes, mijah nowos mapas ijê, néné laki, koening mèsa'nè bagading, njina oembas bidjanè. Djari ènèng tingkahně néné laki, déjang bidję kotjap ta mami'ně Datoe maoe sarěp lëngé si bidjane kadoedoet, lé bidjane endi'ne ara lain, bandjoer minas akal, lés batangne datoe, pina ${ }^{5}$ diri ne dé $e^{5}$ klar, bandjoer Datoe manikang parekan glis, gèn mèsila bidjanè. Léka ${ }^{5}$ kanak mè kèlék Boeling, mè badas ang, tingkahkoe dé kelar, Loe Boeling no kêté bae. Parékan lékas bandjoer, endéně kotjap le langan, glis bandjoer lés néné laki, belatoer sampi njembah: mran kadji tamanikang, gèn měsila, gèn Djero mami péngkadji, děside endi'ne kinjam. Bandjoer loembar néné laki glis, gẽn měmarěk, dateng lế mamis ně, maminè bẻboedjoeng baé, néné laki bẻdjoeloe, datoe bandjoer ngrěngang diris, doeh anakoe pangéran, pasti dé koe baoe, moen dé anté mété owat, mapan ara ling kalépé sadabangkit, $\mathrm{si}^{5}$ bada* 
akoe owat. Djari owatkoe atén majoeng sipoetih jen, ěndi n'ara pasti děs koe onjas, někĕ gěn koe mantar baé, někě apě tingkah anakoe, sanggoep kéno sidě oelati, néné laki no njembah: moeně ngĕno Datoe, koela bĕpamit lés Pĕmban, koela lékas, métě atén majoeng sipoetih, lékas saparan-paran. Glis bandjoer pamit néné laki, bandjoer loembar, endéně kotjap lés langan, wah dateng pakoedan néné, timpal wadon běrasa glis, isis sanak sělapoes, někĕ ngoembé gĕnně si tě, mapan manik Datoe, gěn těnjĕran aning gawah, gěn měmétě, métě atén majoeng si poetih, djari tětamban Pemban. Den Djoeroedé bandjoer glis: mran sila, djĕmas baé tělékas, někě anjargěpang baé, sangoe lan mamas ngoedoet, djemas seloen tělékas glis; bakěna lingde kakas. Endé'ně soewé bandjoer, wah sěgĕp tětimpěsan, sangoe

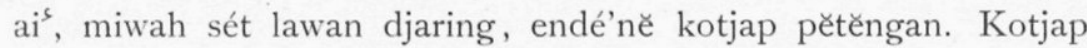
benar bandjoer lékas glis, ngodjos gawah, lés majoeng si moedas, bandjoerně bětroes baé, roewak goenoeng kodés bandjoer, ndéně soewé bandjoerna laé, bandjoer padé bětělah, manik pondok bagoes, ndéně kotjap pètěng désa, kotjap běnar, pangandjoer padě masang djaring, si běgěroh tamě lés gawah. Loewé majoeng baoe $\mathrm{si}^{\text {s }}$ djaring, baga lampar, sěparo telępas, lagoe majoeng djamas baé, talo ai desě bandjoer, masi endénara majoeng sipoetih, kědoeng latjoer lalékan, kětjaritě bandjoer, endéně kotjap taoe si njèran, kotjap Datoe Mamine lés désě Kling, ijě lékang akal salah. Djari Datoe bëmanik glis lé parěkan, lékas dimès gantjang, klèk Dèn Dipatih kěté, dait djoeroe towèk knoně kèté. Bandjar lékas parěkan glis, 'ndeně kotjap lés langan, kotjap ije bělatoer: kadji kaoetoes sis Pemban, sila tamě, dě barěng djoeroe towèk gělis, měmarěk aning Pěmban. Djoeroe towěk miwah Děn Dipatih, padě lékas, tamě pědjrowan, pade lékas gantjang baé, daïtne mandjas Datoe. Raden Patih bètroes mandjing měnangkil, běmanik Datoe gantjang, gawén dak lékoe gěn dě léka' ngangilangang, La Kéntjili, dě barèng Pé towěk glis, adésně plot pisan. Jén 'ndé de glis gěn njëmatés in, La Kéntjili, moele pasti Loe Boeling gěnně sédě, katoengkoel lés ijè baé, adés lékas gantjang bandjoer toer kris koe mèné dè èntï, $\mathrm{si}^{\text {s }}$ aran Boeboeg Rěbas. Dén Dipatih matoer: koela bapamit lés Pemban, koela lékas, aö anak La Kéntjili, djĕrapo dě sěmatés ijè. Bandjoer pamit Den Dipatih glis, sampi njéngkéng, kris patjanangan, padě lékas gantjang baé, Dén Di patih bětroes, bandjoer dateng lé néné bini, daïtně ijĕ bariwa, 
těkotjapang bandjoer, wajan bidjaně nem boelan, Dén Dipatih běmanik sampine Tjïli, gawéngkoe kěté něngkě, akoe těmanikang $\mathrm{si}^{\mathrm{s}}$ Datoe glis gen njěmatés. Néné laki matoer bĕri's mran kadji no bělatoer, ěnděpon kadji banggas lés manik, anging panědě amla, lés péngkadji Datoe, kadji toenas towos ijě, anak kadji, mapan kadji patjang matés, sai si gĕn nowo ijĕ. Aö něngkě manik Dén Dipatih, sok lés gantjang, béjang ijě mangan, pos tělékas gantjang baé. Néné bini no bandjoer, pos ně towos bidjaně glis, sampině dédé ijě: doeh dén noeně bagoes, běsoer ${ }^{2}$ sidě mangan, mapan akoe gen glis ngĕmasin pati, ité po side mas mirah.

Oewah djraně nowos néné bini, Dén Dipatih bandjoer anjěrěkang, někě èntah bělékas baé; néné bini balatoer, kadji noenas soekan péngkadji, gěn kadji pandi ijë anak kadji djoeloe, béga ${ }^{2}$ mělah, mapan kadji gěn djra gěn kadji ěntik anak kadji lés doenja. Něngkě pandi, manik Dén Dipatih, sok běgantjang, adé glis lékas, 'nda katoengkoel soesah baé. Nnené bini no bandjoer, endés pon ara gěn soesah kadji, gěn maté tělangang, mapan soekan Datoe, oewah moelě gěn kadji tinggal, lés pon doenjě. Nene bini bandjoer glis, ijě mandi bidjaně. Oewahně ijě mandi bidjaně Den Dipatih, bandjoer bĕmanik, èntah nĕngkě lékas ${ }^{s}$, enda katoengkoel badédé. Néné bini bandjoerně glis: sila péng kadji loembar, kadji ngiring bandjoer. Den Dipatih bandjoer loembar, djoeroe towèk, léka'ně noedjari moedi, néné bini lés těngas. Bidjaně noe sampi ${ }^{\varsigma}$ ně tědongin si $^{\varsigma}$ lémpotně, lémpot kamalině, bandjoer padě lékas, lékaně no saběbaris, bandjoer pade batroes, néné bini sampis ně bĕmanik, si ngaroemroem bidjaně, doeh dènoeně bagoes, sipi tan koe kangěn sidě tan koewasě, akoe kangěn sidě Goesti, ěndénara tan koe oenas. Kotjap bandjoer tingkah néné bini, oewah datěng lěndang loewah désě, taos ně si gěn těmaté, Dén Dipatih no bandjoerně běmanik lés néné bini, sis ně sigěn taga'lah, boetěng něngkě kamoe, ité'ně taos koe ilangang; néné bini bandjoer bělatoer manis: moen atoer koela déwě, kadji noenas ito lés sisěpi, taos kadji sigěn tailangang, sindés kaseban kalépé, jèn kadji bětroes těsěmaté lés lěndang sěné, mapan parěk lés désa, éras baïsan Datoe, onja sila ta bĕrenggang, lés sisĕpi, ito lés Lĕndang Měnangis, taos kadji ta ilangang.

Dén Depatih bandjoer ma'ati ${ }^{\text {, }}$, bandjoer léka, si ngodjos tan- 
djoengan, léka-něno adéng ${ }^{2}$, bandjoer malik ngaroemroem, lé bidjaně si gěnně bilin, doeh anakoe pangéran, jen dě boewas njamboe, koepasakit sidě oental, mapan toeně, sidě mirah gěn koe bilin, doeh Goesti mas pangéran. Toena ${ }^{5}$ lalo sidě mirah gěn koe bilin, lés bon doeniě, ini ${ }^{5}$ lalos sidě djari manoesě silaé, dě djari dara ${ }^{5}$ adjoer, gama laé dě djari ai ${ }^{5}$, enda dě djari manoesě, aténg koe no bandjoer, pitlah si gěn tělangang, něngkě ngěné, po djarin dě néné goesti, minak kadaran ninandě, minak soesah aténgkoe baé, něka mirah dě soenjoesoe, gati ${ }^{2}$ sampoeng koe oerip. Bandjoer njoesoe bidjaně, sampi ${ }^{5}$ ne $\mathrm{si}^{\text {s }}$ idoek, bidjaně sampi ně djadjam, doeh mirah, ngoembé sang djarindě goesti, si ${ }^{s}$ bilin koe lés doeniě. Dateng bandjoer lés Tandjoeng Měnangis, bandjoer mandjak lés bawas kětapang, bilě denganně běréndés. Dèn Dipatih no bandjoerně běmanik lés néně bini, něngkě baoerěs gantjang, toer baingět bandjoer mapan kamoe gen tagalah, si Pé towěk, nengkě bědjra anak bětokolang ijě nengkě. Néné bini bandjoer matoer glis, doeh pangéran, atoer koela déwě, gěn kadji mětanggah baé, kadji njoesoewin djoeloe anak kadji adés tan něnangis, si gěn kadji bili ijě. Den Dipatih njamboet, aö nekě soesoewin ijě, sok běgantjang. Bandjoerně njoesoewin glis, sampině idoek djadjam. Ité sidě nèné laki, onja ${ }^{2}$, ité side, enda ${ }^{5}$ dě gila nangis lalos, mapan akoe gĕn koe tinggal lés bon doeniě, ao tao sidě ngaoelajang awak. Den Dipatih bandjoerně běmanik, ngeno ${ }^{2}$, si badédé anak, katoengkoel badédé baé, néné bini no bandjoer, tokolangně bidjaně glis, sampi ${ }^{s}$ ně idoek djadjam, doeh noeně bagoes, měné sidě boewas bilě, děpědékang, ité sidě néné Goesti kadji pamit mas mirah. Bandjoer oerěs néné bini glis, bandjoer ngoetjap, djari ling atoerně, isi ně sigěn těmatés, bandjoerne njoegoelang atoer: atoer kadji Raden Di patih, moen kadjï moelě pandjak, sarĕm minanglaöen, sědĕg kadji si tagalah, dara ${ }^{5}$ kadjï abang toer mamboeně baïs, těri sěbo $\mathrm{li}^{5}$ tana $\mathrm{a}^{\mathrm{s}}$; lan sěmalih Raden atoer kadji, lamoen kadji, toera sing koesoema, péngkadji njarěminang baé, daras kadji si soegoel, toer mantjirrat taék aning langit, poetih warnaning dara ${ }^{5}$ toer mamboeně aroem, no atoer kadji endas loepas les dě kadji, pèngkadji njarminang pasti, sědi kadji tagalah. Bandjoer parěk djoeroe towěk glis, $\mathrm{si}^{s}$ njenkéng, kris patjanangan. Den Dipatih pinang baé, néné bini no bandjoer, běsidakěp matja sadat glis, djari oewah toetoes sadat, djoeroe towěk bandjoer, 
galahně lés samoegině, néné bini, moentjirrat gětihně poetih mamboeně sěngér ngajangs, toer gětih no taék aning langit, néné bini, bandjoer oewah sédě, maras sině ěntjep baé, Den Di patih no bandjoer, djaït gédéng kětapang glis, bandjoer něroeroep ijě, wahně si bĕroeroep bandjoer posně padě lékas, bilin majit, lékasně nemoe bilai, Pé towěk běrarasan. Karanté děngan Dén Dipatih, inas raden, ling si taïlangang, pasti endés ně sisip baé, moelě djati taoe agoeng, épén bidjě djari sasěné, sengka'ně ndé salas basa, djoeroe towěk bandjoer, datěng langan boental ime, katělěr mata, bandjoer endé'nè gitas lai, kajoe batang lamparně. Idoeng djangoer běgaritas bĕgaritik, bis kĕdampěs bilang kajoe batang, Den Dipatih pinang baë, djoeroe towěk bětroes běgagarap ngodjok sasawing, bandjoer ně tĕri otak, lěboer lés boen poepoe. Den Dipatih bandjoer kotjap oewah dateng lés bantjingah dateng Kling, daïtně Datoe mandjak. Bandjoer Datoe no glis, oewah ké pisan, sidě ngilangang. Den Dipatih matoer: mran kadji bělatoer Goesti, koela ngatoerang basa Kéntjili moen kadji toeras toer pandjak,

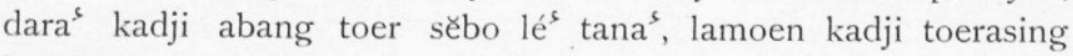
koesoema, pasti mamboeně sěngér ngajang, toer moentjirrat taék aning langit, no talingně, bandjoer tetoelingně, mamboen daras sěngér baé, troes Pě towěk bětroes, pěkék mata idoeng ngaritik, bandjoer endéně gitas langan, nimpoh lés sawing siatas, ijě matés bětroes, těri lé tété tanas. Datoe momot, padè běnga tětoetoerin, endé'nara lingně ngoetjap.

Eněng Datoe silés désa Kěling, kotjap Pandji, si ${ }^{s}$ lalo njĕran, ijĕ ngimpi kaliwat lěngé, impině mirahně leboer, si pina'ne mata $a^{5}{ }^{2}$, bandjoernĕ tagèt ngasĕ; sanjasanam bandjoer bělarine aning désa, Wiroen Kalang, Togok Sĕmar ěndé'man tangi, salas sopo ěndé’ně ngasě. Kotjap datěng désa néné laki, baketowan lés talin oembakně, ěmbé lain anakané, talin oembak no matoer: doeh mas mirah sanak péngkadji, oewah maté taïlangang, tao'ně lés tandjoeng, Den Dipatih ngilangang ijĕ, těmanikang $\mathrm{si}^{s}$ mami péngkadji Goesti, 'néné laki no loembar. Bělarina néné laki glis, ngodjok tandjoeng, endés kotjap lé langan, kotjap gantjang dateng baé, sadatěngné lés tandjoeng, néné laki gédéngang tangis, bidjaně kěpanasan, sarminang bandjoer njoesoe lés lajon mamisně siwah sédě, bandjoerně těpět ijĕ glis, datěngně bandjoer rebas, pasti endéně ngasě sakali; sahasaně no bandjoer, bito maras 
kalépé bini, sampisně ngiwa bidjaně, gadingangně bandjoer, těděs si bini iwaně langan kanan, bidjaně no langan kiri, néné laki bědjadjam. Ené peno djarindě mas Goesti, si bilinkoe njěran aning gawah, kadingkoe tao sakěné, endékoe mélés těsoeroe, isi děngan gěn sara laï, kaling ngěné siněngkě, tětoengkoelang akoe, ara langan da ta séda isi děngan, endéně sala $^{5}$ lingdě goesti, lingdě sidjoeloe mirah. Doeh dèn noeně néné laki, sala ${ }^{5}$ lalos, panemoen de mirah, děsandang narakě baé, moga němandi poedji koe, po koebarěng maté sěkali $\mathrm{si}^{\mathrm{s}}$ inande mas mirah, dikakoe sï̈doep loewès lalos genkoe sandang lés bon doenja, la sijankoe barěng maté $\mathrm{si}^{\text {s }}$ inandě mas pangéran.

Djari ěněng tingkah néné laki, kotjap sanakaně ijě masi tindoek baé, Sěmar tangi djoeloe, ijě dodos batoer glis, bandjoerně padě měméta, bilang gawah goenoeng aningně si padě měméta, endéně daït néné laki si bělari, bandjoerně ngodjos désě. Datěng désě masih endéně daï, néné laki, bandjoer bakatowan, maoe srěgěp gantjang baé, bětroes aning tandjoeng, dé soewé bandjoerně daït datěngně papa ngělah, padě nangis bandjoer ngaroh maras taoe nině, sělapoeně sinangisin néné laki, baga golo bagagowah. Sapénang a siwah padě nangis, Den Djoeroedé, mwah sanakaně, bandjoerně bělatoer barés: mran kadji bělatoer, kadji noenas soekan pengkadji, toenas kadji paréntah, endés péngkadji bingoeng, oewah toedoeh isi ${ }^{\text {s }}$ pangéran, oeli sila, těbarěsin lajon no glis, bandjoer těpaděmijě. Néné laki bandjoerně běmanik: adoeh kakas, koe mindah lés sidě, gěn koe barěng bandjoer baé, aloerang adés ně lěboer, lés iwas koe koepina $^{s}$ boemi, lamoen dě talětijě, blés pamindah koe. Dén Djoeroe dé bandjoer ngoetjap: kadji noenas ngiwa bidjan péng-kadji, désidě endéně soekě. Bandjoer kotjap soewé néne laki, sibariwa, saking kasoekas Alah ara pitoe djělo bahé, bandjoer ara toeroen swarě no lés néné laki, ling pangoetjap swarě, sidě noeně bagoes, lamoen tětoe sidě toeně, si gita ${ }^{5}$ ijě épén baléndě no pasti gěn koe bada sida noena.

\section{Semaran Daně.}

Dě pijasang ijě glis tablě, po pe tamang ijě gantjang, bandjoer dě tali ijě bélo, pos dě timpoh lés sěgaré, talině ěndä djras, 
ěndas ěntik mipir lés laoet boe, érak malik idoep ije. Oewahně

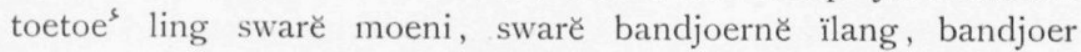
glis néné laki no barĕng si sanakně padě mijak tablě gantjang, ěndéně soewé bandjoer poetoes, lajon no bandjoerne tamang. Wahně tamang, po'ně tali tablě $\mathrm{si}^{s}$ tali émah, tali těsamboeng bélo, posně timpoh lés sěgarĕ; béloně talin tablě, séwoe děpa lan sapoeloe tloeng dasě lan pat děpa. Endé soewé néné laki sagadingang talin tablě, bandjoer napĕgat talino, néné laki bandjoer běngas, sinjarminang talin tablě, tablě no bandjoer bětroes éléně satiba para.

Salaésně néné laki, simipir sědi nemporan, aras oewah satoes djelo, laḯně mipir sěgarě, moena lapar bidjaně, si bobong kajoe těbaoe, sino sisně mapas ijě. Bandjoerne běmanik manis, néné laki lés bidjaně: "doeh pangéran koe mas mokol, koearanin side někĕ, mapan sis koe kampowas lés inandě noeně bagoes, Mĕgat Sih arandě mirah. Salaés ně lés pasisi, néné laki lés bidjaně, bandjoer maraminas pondok, pondokně si nganti ijĕ, nganti ně soeka Alah, tablě sangně katěmoe, noedjoene taamporang oembak. Endé'ně soewé néné laki, sitěpěkonté tjarita, kotjap Datoe balalangon, Datoe silékan lé Děhě, balalangon lé sěgara, tairing $\mathrm{si}^{s}$ toembak toeloep, bědil kalěm lan kaléwang. Lan ramé gamělan moeni, si ngiring Datoe si loembar, pade ramé pangiring no, djari endé kotjap lés langan, kotjap datěng lés sěgarĕ, bandjoer padě mandi rawoes, table sajan bětěngas; lamoene padě běsědi, taoe sigěn ngemboen ijě, tablě běsědi ijě ngodjok, sakěno baé tingkahně, ngrasě padě ngělah, bandjoerně bamanik Datoe, maé akoe karing kanak.

Bandjoer loembar Datoe glis, si ngodjok sědin amporan, table běsědi ijě ngodjok Datoe bandjoerana gantjang, parěk datěng table, gagak poetis bandjoer kětjoer. Datoe bandjoerana djawat, bandjoer taékangně glis, ngorosne aning amparan, kaoele bandjoer měmopong datěng darat, tokolangně Datoe bandjoer běboeka, těboeka séloeně tandoer, tjahjě manoesijě isině. Pơne sangkol ijě glis, Datoekoe né gadingang ijě , bandjoerraně glis těpopong, taékangně lé djěmpaně, Datoe liwat soekaně, singěmboen dědarě bagoes, Datoe no bĕmanik gantjang: doeh mas mirah néné goesti, tingkah si daït sidě, sasatkoe daït mas mongkol, lés těngas laoet sigoewar, někĕ side dén darě koe pija anak pamoentoe, mapan koe endé déjang anak. Něǩ Datoe siběmanik, kotjap bandjoer padě lékas, tjatoe 
mwah pangiringně, néné bini lés djempaně, těkatir isis kaöelě, tairing $\mathrm{si}^{\text {s }}$ toembak toeloep, bedil kalem lan kaléwang. Lan ramé lan moeni, ramé ongkat taboewan, ramé soerak ramé kopok, djari kotjap lés langan, kotjap datěng lés désa, Datoe no tamě bětroes, toeroen tiba patmasaně. Bandjoer mandjak néné bini, Datoe bandjoer běpangarah, njoeroes taoe noedjas baé, mwah kajoe baoe ${ }^{2}$ batang, mapan $\mathrm{si}^{s}$ tě liwat, gawé blés gěnně tangoen, gěnně njĕlamětang bidjaně si bĕroe maoeně daït. Bandjoer tapěkonté tjarita, ramé ongkat gong gdang no, djělo kělěm ěndésně pěgat, nanggěp topéng lan wajang, djogét barong lan gamboeh, legong topéng ramé padě, soeling rědēp ramé moeni, tandang djodjor tandang dadap, ramé tandak ramé gĕroh, Datoeně gěn pariséjan, raména kaliwatan, ramé gendang ramé kempoel, Datoeno kaliwat soekě. Datoe no bĕmanik glis, lékas dimès gantjang kanak, mès lékang ara bĕrĕm no, mapan koe ngipoes kaoelě, siné si parisejan; endé ně soewé datěng bandjoer taipoek siměton padě, eneng pariséjan sasěné: Kotjap lés dalem désě, padě ramé noedjak baé, nině mamě gajoer pangan, minas wadjik no padě, sělang gěntis si bagajoer, pangan liwat dodol nangka.

Eněng tjarita sasěné, kotjap Pandji, barĕng si bidjaně, barĕng si Sĕmar lan Togok, mwah Djoeroedé lan Kalang, si mondok lés amporan, Megarsih wajaně bandjoer, wah bědoewé kěkarěpan, anging karéré Měgarsih děngĕrně ongkat gamelan, ijě sěno soekĕ nĕno, no taroewan těkésně, wajanně tao bawastra, tkésně bělari, bandjoer bakatoewan lés mamisně, ongkat ape sino manik, si ramé ${ }^{2}$ ongkatně, mamisně no nimbal barés, jén koe badas sidě mirah, masan dě taos ijĕ, doeh anakoe noeně bagoes, Datoe Dewě běsasoekan. Bandjoernĕ bĕmanik manis Měgarsih datěng mamis ně, pasilas ně gĕn mamaö, mamisně bandjoer kéwoehan, 'ndénara si nĕnimbal, soegoel manikně ngaroemroem, adoeh anakoe pangérans, 'ndés dě bani néné goesti, Datoe Déwě běkarije, taoe blés běris manto, 'ndé tě sĕměl gěn těgita, singěné ïta roewanta, dě ta mara roewantaoë, karéréně isi dengan. Megarsih bandjoerně nangis, baga golos baga gitak, mélés lalos gěn mĕmanto, mamis ně bandjoer kéwoehan, 'ndénara lingně nimbal, doeh anakoe noeně bagoes, sidě njonggat angěn mirah.

Soegoel manikně basrěmin, apě ling koe badas sidě, doeh pangéran koe mas mongkol, silas tédjak mamis kakas, sangně Dl. 67. 
sěměl si lékas. Měgarsih bělari bandjoẹr, sadatěngně bandjoer ngoetjap.

Bandjoerně běmanik, glis tě na békés akoe mojě, raden Wiroen nimbal barés, doeh anakoe mas pangéran, Datoe Déwa běsasoekan, dě tasěměl noeně bagoes, gěn těgitas isi dengan. Bandjoerně édjak ijě glis, Megarsih bandjoerně oembak léka ně bandjoerně sangkol, lékas bandjoer padě gantjang.

Endé'ně kotjap lés langan, si ně léka radén Wiroen, bandjoer dateng djěbak Děhě. Raden Wiroen bandjoer glis běsěbo lés bawas lambah, Měgarsih no tjingok tangès si děngěr ongkat gamělan, djari ara manikně, ěmbé tao mami Wiroen, singeni ${ }^{2}$ ongkatně. Radén Wiroen bandjoerně glis, taos ně lés dalěm désa, Megarsih běmanik barés, ěndésně ngěno mamis kakas, koe kěto manto ijě, apan $\operatorname{sino} d e^{\varsigma}$ koe taos, koe pědasang ijě tjoba. Ité sidě těpoe mamis, gěn koe lalo mědasang ijě, sangně baoe gěn koe panto, koe pědasang ijĕ tjoba, Raden Wiroen no ngoetjap, endés ně baoe noeně bagoes, loewé lalo taoë mojě. Endésně kěto néné laki, ilat sidě si děngan, mapan taoěs loewé manto, Datoe Déwa běkarija, Megasih ěndéně soeka, bandjoerně loembar bětroes ngider lés loewar kalangan. Kotjap Wiroen sita bilin, besěbo lés bawa djarak, mara séwang tingkahně no, soegoel tamě djabě koetě, mapan 'ndénara kéréngně, Měgarsih bandjoer batěmoe, kělépé nině gitas ijě.

Tawongan nira Toewan Déwi, toemoning sang wawoe praptě, andjiwil padě rowangé, raré pěkik ikě praptě, lah parananě énggal, adjakěn mangké maľ̌boe, ing djro marěking rahadijan. Toemoelija mangké marani, anamboet asta ikě, ki bagoes sarěng nganonton, lah pajoe mandjong djro poera, Raden Poetra ngoedjiwat, toemoelija sarěng maľboe, prapténg ngarse Toewan Déwija. Kapanggih sira Toewan Déwi, eling sira ing atmadja, kang poetra sinamboet mangkor, ingaras aras tasira, doeh njawa anak ingowang, sira tan panděrbé iboe, anak bapa kawlassarsě. Medalloeh ira Toewan Dewi, ingoesapi wastra nira, doeh njawa boekti ingkéné, sang poetra tanarsa dahar, aroemroem dening sang dijah, dahar djawadah tan pajoen, anoelija dinoe san sira. Woes ija siniram sini salin, wastra widjiling djagatra, pinarada toehoe kaöt, saboek gringsing toer masoelam, imboeh bagoes ta sira, lir widadari toemoeroen, kanganonton kawěněngan. Ling ngira Toewan Dedéwi, jen sira mantoek masing wang, ingsoen nakirim pangagong, nem parakat katah neka, 
warahan raman ira, mangké ta pa soengsoeng ingsoen, anging datan soemapala. Lan wěwěkas ingsoen kaki, warahna raman ira, béndjang méréné no nonton, wongagamboeh ing paséban, anggen ingsoen wikana, roepanija ramané bagoes, adjata nora nontoně. Anoelija dépoen-asoegi, pagaroněm padjengan, sekoel oelam djawadahé, woes winadah sinidjenan, sangsoe Déwi angoetjap, lah amoeli mirah ingsoen, élingěn wěwěkas singwang. Kinon něngatera midjil, pawongan anampa wastra , djawadah sěkoel oelamé, ikě oewas pade binakte saprapte ni reng djaba oeloengan daga katemoe, pinaran dening sang poetra.

Jata poenang angateri, kangagawa sekoel oelam, djawadah mwang panganggo, kasrah ing oeloean daga, anoelih sira linggar, andaga noelih sang soenoe, tan kawarna sireng marga; Prapta ingalas panjingid, noelih ingatoer sadaja, ing rama sakèh pawèh wéh, paweh ira sang soedéwija, mwah pawekasira, toewan galoeh ika woes katoer, toewan Mantri mangké kapanětan. Kidjoeroe de' matoer raris, adoeh goesti ingsoen déwa, paran wekasira mangko, dadi koetoening pawana, twan tindakakně, ing nĕgara anglilipoer prijatin manawa soeda.

Jen oepaman, dika goesti, amoetěr něgaréng Děhě, manawi sakti mangko, jan anderbé poetra parawan, abětjik naïka, wernané andika tjoepoe, djaloekně oega pangéran. Masa tan pawéh narpali; apan rama pakanira, asanak lawan sang katong, rahadijan nangrěs kapanětan, kakang loengě ing bondjang, ing negara anglilipoer, rika nata $\mathrm{kira}^{2}$. Jen ingsoen lipoer sadidik, irika sama nginěpa, kadang kadéan natoeré, alerěs mangkana déwa, adan samija dahar, étja dénija anjekoel, toemoelija dahar djawadah. Warěgan noelija ngamběli, woesija nginang atoeroewě, tan lijan kang apti mangko, kaka werta dening poetra, pan kaja iboen ira, marma lěrěs twas sira gagětoen, tan kěně arip ta sira.

Soeměkar asaning ati, aroengoe oedjaring poetra, lir amanggih soerija mangko, ring madija latri goemawang, lir katiban ratna, sasangka tiba andaroeng, mangan naoelah ing nale.

Datan kawěrna ing latri, mèh rahina atoeroewa, tana soewé panidrané, éndjang samija atangija, noelija sami asiram, mangké sira salin kampoeh, pawéh irahadén déwija.

Anoelija sami loemaris, anoet marga maring Děhě, prapta 
ing désa lampahé, akéh poenang wong kapapag, sing kapĕndak manděga, égar panděměn nandoeloe loewar né sang wawoe prapta; Pada sira miloe ngiring, déning wong arsě moelata, dadi akéh pangiringé, dening wong arsa moelata, ratoe oendangan prapta, kangiring sěsěk soepěnoeh, tan nadoh kadéjan nira. Lakoené angonang riris, warnané kadi lir soerat, gawok sakéh wong anonton, samarga agogondjakang lanang wadon girang, raré toewa akéh andoeloeh, kěběk doeloeroeng oeriran.

Moenggah sira pantjaniti, satrija moengging paséban, presamija toeroen agé, iděp ira ratoe prapta, oendang oendangan děsa, pan doeroeng sira andoeloe, mangkana iděpinala.

Sapraptané Raden Mantri, lagi angaděging natas, satrija anapa alon, daweg moenggah sang datengan, sahoering rarahadija, singgih pajoe sarěng loenggoeh, jata sira sarĕng moenggah. Woes tatah denija linggih, ajoenikang para nata, ki patih anapaälon, tabé ingsoen natanija, déning tan wròeh manira, těmbé mangké atětěmoe, saking ngěndi sangkan nira.

Mwah djęnĕng ira Goesti, waktjana ingsoen twan, Rahadén. Mantri saoeré, héh Patih inggih manira, ngong datěng saking ngatjala, saegén egénna toeroe, wong loembaritan padesa.

Noelija mandjinging djiro poeri, oematoer ring toewan galoeh ika, asěmoe pragataha mangko, singgih Déwa Soesoehoenan, raré pěkik woes prapta, sarěng lan raman nirekoe, sampoen aloenggeng paséban. Soen tingalě wěrna něki, mangkana kaja asĕmara, wěnéh kang mĕgěp polahé, djěněng ira kadi rangga, mangké ingkang sanoenggal, prěkasa kras dinoeloe, warnané sawidji ika. Bagoesé galak amanis, raga kadi djiněpitan, kadija ngoen nangoen wěrnané, kang sawidji kadi sěmar, lěmoe abědél ika, wětěngé kaja toehoewoeng, paësi poenang rorodan.

Sapari polahé moengil, awéh goejoe ing paséban, sawidjï boedjil aděgé, tjoengoer limo ta goejang, oedjar ré tjarétjédan, sapolahé awéh goejoe, rěměn wong kang anonton. Kang nging atoeran tan pangling, pan sam poen karasa ing twas, dijan mantri lan kadejané, tan lijan prapta ing djabé, parěngi poetran nira, rahadijan déwi noelija adoes, woes siram noelija pajas.

Anganggo Radja kang poetri, liwat ajoe warnan nira, lir ijang ratih warnané, anoelija mědaling djabě, ngaděging panindjowan, wong ira ngiring soepenoeh, lawan poenang kakang kakang. Noelija sira Radén déwi, awas ikang raka prapta, lawan kadang kadéjan, panta ilang ing koeñě, toemingal mědal kang loeh, 
wétning kagěng aning trěsna. Toemoelija toemoeroen naglis, marani sang wawoe prapta, sang pinaran těmjoeh twasé, toemingali toewan déwija, marman nira kaliwat, dening pinaranan ikoe, dén nira sira sang déwija. Toewan déwija ling ngira aris, doeh pangéran soesoehoenan, trěsna těměn dika mangko, wěnara agingsir ring oebaja, doeking ngěmbakang pĕdjah, liměboeh ěně ing laoet, winadah aning tablě.

Kang tangis ngrasaning ati, radén mantri ngrěngkoel sirě, kakalih drěs warpané, samija nangis tinangisan, rangkoel rinangkoel pada, radén mantri lon amoewoes, adoeh njawa arin ningwang. Dan sira parě narpati, mwang kang para poenggawa, sěsěk tansoeh werdajané, déning sang déwi koela, tan wroeh paran ningwang, kawěngan sira andoeloe, ana matoer ring sang nata. Rahaden déwi ing Djawi, angrangkoeli sangdatěngan lintang kagété sang katong, midjil' sakarolan tjengak, sang prapta nirang djaba, atakén nira dén galoeh, sapadéwa rangkoel ika. Sangpoetri saha saoer bakti, sawakta atoer kaoela, iki poetrané sang katong, ring Kling raka andika, oeni sira akésah, ngoelati rabi alampoes, tana étang pati gěsang. Manira kangdé noelati, bésoek toewan amba warah, jen woes prapta sakabéhé, ratoe ngoendang ${ }^{2}$ ika, mowah andika, ratoe Kling istri kakoeng, adja tanora nakěně. Mowah sira Bibi Kili, adja tan kěna ingoendang, kalih kalawan somahé, poma adja nora kěně, oetang agěn lintang maring Bibi Kili ikoe, sang nata aris ngandika; Lah sasakrasan nira nini, sang noelija poetoesan, angatoeri raka agé, istri kakoeng ing djenggala, miwah ni Bibi Kilija, sasomah ira kang toetoer mara ing něgaréng Děhě. Oetoesan loenga aglis, sang nata aris ngandika, lah nini mantoeka ing djro, sarěng lawan kakang ira, kang poetrané kinamban, agé pada datěng těmoe, lan Bibi ana ing poera; Radén déwi angatoeri, kang raka kinanti asta, sarěng maleboe ing djro, anakira woesing ngěmban, angadaton sadaja, sapraptan-ira ingajoen, ni bibi loenggéng padapa. Měděk kalih awot sari, praméswari atatanija, sapa nini sarěng ing djro, tan bontěn ing soen toemingal, těmbé ing soen toemingal, Toewan déwi němbah matoes, iki anak ira twan.

Poetrane sang radja Kling, kotjapa kang brangta ngarang, loenga ngoelati rabiné, kang mati moenggeng table, amba iki doeh pědjah, mangké ta amba katěmoe, ring djaba lan anak toewan.

Poeniki rěké kang tjili, poetran ingroen kaoela toewan, jen 
woes raoeh sakabéhé, para ratoe ingpadésan, miwah kang raka toewan, ring Kling saïstri djaloe, ika atoer wakta. Lan sira ki Bibi Kili, sasomah iraden oendang, dening rakan di ka mangko, besoek ija jen woes prapta, ika twan wikana, ring moelah ta boektan ipoen, mangké amba atjarita. Lah sakersan nira nini, adoeh kaki anak ingwang, lintang soekoer séwoe ningong, sira datěng tan pawarta, aglis pramésowari, goeroening poetri rinangkoel, adoeh kaki anak ingowang.

Poen iboe kaja angipi atěmoe lan nanak ingowang lir amanggih ratna ingong, toemiba saking sowarga, lěga ing manah ingowang, lah pada ing kéné maskoe, anak mantri ing Koeripan. Raden mantri saoer bakti, singgih sahandika toewan, noelija sami linggih mangko, praméswari rinamboeta, poetoené pinakoewan, ingarasaras rinangkoel, noelija raoeh kang djawadah. Apělak wernanija pasti, jata adaär djawadah, hakěmboel lawan poetrané, tjatoeré lan poetoen nira, saoes sira adahar, amběngé ika woeskatoer, étja dénija karaméjan. Wong djro marěka sami, lintang soeka nalan nira, andoewé goesti roro, katiga lan poetran nira, motjoróng tjakijan nira, lir déwi natih toemoeroen kakalih lan ijang asěmara. Kawěrnaha Sri boepati, sijang daloe, akasoekan, sajan nawoewoeh boengahé, kawěrnaja kang oetoesan, woes prapténg ing Koeripan, sang praboe katoedjoe mětoe, pinarěkang néng paséban. Kang oetoesan noelija praptě, oemarěk maring sang nata, aněmbah oematoer alon, kaoela ingoetoes toewan, dening raji ankika, sang naténg Děhě poekoeloen, angangatoeri pakandika. Kalawan raï sang adji, sarěng lan nandika toewan, toemědak maring besoeké, dépoen katoetoeran oega, pakré pranagata, dépoen toeloesta poekoeloen, sih ira mangkoe prěgata. Pan sira inarpati, olih anak roro toewan, samija bětjik lanang wadon, mangka amrěsing poetra, sinaksen naning séwa, sogata lan pararatoe, darapon samija wikana. Sang praboe nangoeri aris, lah ingsoen béndjangě lomga, sigrah kalanan sakéhé, rabi ning para poenggawa, héh patih arahěně, sěrgěp kang adjoli tandoek, koeda lan samapta nira. Noelija loewara narpati, mantoek sira ngadatwan, saprapta nira nèng djro, awarahing rabin nira, bendjang loenga ing Dehĕ, pramésowari wot santoen, kakang adji sahandika. Kawarnahě sira patih, woes sawarah para mantja, sang praboe lanan rabina, béndjang loenga maring Děhě, samija atjadang koeda, mwah djoli lawan tandoek, ni Kili woes winarahan. 
Endjang adan Sri boepati, lawan pramésowari nira, woes midjil sira sang katong, agrihan wong angiringang, pangang gonija brang sinang, pěpěking djabě katěmoe, mantri poenggawa ngantija. Toembak toeloep pada moeroep, inon lir sěkar sataman Woes moenggah mangké ring djoli, sang nata lan pramésowara, pada ingoeloer djoli né, poenggawa anoenggang koeda, noelija sami loemampah, tan kawasna siréng ěnoe, prapta ing něgaréng Děhě. Pinapak sira narpati, dén nira sang naténg Děhě, ingdjawi koeta pěrnahé, sapraplané raka nira, jata matoer ana, kakang adji wawoe raoeh, sarwi sira awot sěkar. Rakan nira ana oeri, ling ngira sangetipoen kakang pramés wari sinapa agé, sahoerré kaoela toewan, adan samija loemampah, prapténg pantjanniti sampoen, loemaris maring paséban. Sang nata Kling alinggih, arěping sang nateng Děhě, panarěking para katong, sira sang naténg Gegelang, oeni sira woes prapta, lang sang nata Singasantoen, atatah linggih adjadjar.

Séwa sogata alinggih, ing ajoen sira sang nata, prameswari angadaton, kapanggih lan pramésowara, ring Děhě dahar wowohan, asoekan soekan tinamoe, lawan pangiringé ika.

Ring djawi Sri narapati, sampoen katoerana moentjang, Séwa sogata sakéhé, mwah sakéhing pangiring sampoen, pada sinoengana moentjang. Warga dalem laladéni, panganggonija loewih loewihan, sami patoeh tajoingané, midara ngatoeri tjanang, gamělan tinaboehan, agrah sowaranija oemoeng, wong kanganonton éběkan; Kawarna Rahadén mantri, kalawan sira jinira, woes pajas panganggé agé, kapanggo radja djoewita, jě éběk warnan nira, istri ajoe lanang bagoes, kadi ratih lan asěmara. Kaka ling sira amidjil, Djĕnggale lan Këdiri mangko, wong sinělir angiringang, woes prapta ing paséban, apijak poenang wong Kakoeng, pada doh sira loenggwa. Para ratoe atap palinggih, balawan séwa sogata, Sri pramesowari karo, alinggih sanding sang nata, anakira kalijan, woes sira sama aloenggoeh, sanding sang naténg Gagělang. Tinontan kadi ring toelis, égar twas sira niningal, pan sampoen atatah kabéh, tan sipi soekan ning manah, raden déwi matoerě, pasang tabés manira poeniki, ring sira kang para ratoe, sowaraning lir madoe drawa. 


\section{Tembang Dangdang.}

Pasang tabĕ manira poeniki, toewan sama; agoeng siněmpoera, menawi ana sisipé, kaoela noetoes ${ }^{2}$, tjaritané ratoe ring ngoeni, lingé sapara nata, dawěk anak ingsoen, agépoen bapa mijarsa, noelija matoes, amětoning woewoes ija aris, ana ratoe ring Děhĕ.

Panale mitané derbé poetréki dén sang nata, anéng Kling sisa, tana derbé poetra rěké, ija ta sira sang praboe. Děhě minah ratoe ring Kling, samija loenga něněda, sigrah anéng goenoeng, alabakti ring Kajangan, ring Batara, sapraptan nira ing oekir, ratoe Kling matoesa. Ring kajangan ratoe Děhe dimin, panědané, irika Batara, atoerta kaoela mangké, aněda doewé soenoe, istri sidji jankatkani amba ngatoerang segah, poele toera aroem, oelamé maëndah warna, saisining, darat lan isining warih, adja nana kirangan; Lan wernaning djawadah sami, adjanana, koerangé sanoenggal, soesoeh wangi sadjambéné, toenggal wědalanipoen, soen ngatoerang tda mariki, miwah toenggal raïna, soen ngatoer ang sěkoel, mang lingé sang nata, ratoe Kling, samangkana atoer néki, anéng sira Batara.

Jen kaoela děrbé poetra sidji, toera lanang, kaoëla ngatoerang, š̌gah sarěng saoëlamé, ing godong woes lajoe, djawadahé tan pageni, masahatan kraséng toewan, anging nista ratoe, djawoh salah amědal, mangkana naling, sira sang praboe Kling, praboe Děhe goejoejwa.

Nista temen poenagih kakang adji, lir tan ratoe agoeng amangkoe rat, sang praboe Keling saoeré, kédep adanipoen, katekan nawěwĕrat kalih, prameswari Djenggala, mwah ling Děhĕ sampoen sãmija sira awewarat, tjénarita, woes kěkěplé kira kaléh anoelija tasira babar.

Lanang poetrané sang praboe ing Kling, praboe Děȟ, wadon poetrannira, praboe sawědalé, prapta toenggalé wetoe, tan natoewang sira atoeri, bakti siréng Batara, pélak warnanipoen, praboe Děhě nora sirě, angaloerang bantěn sakadi ling neki, poetra malah diwasa.

Sira Batara pan kaliwat roentik, ring sang praboe Děȟ tan tindihě pan linjok maring sanggoepé, anoelih sira ngoetoes, 
liloes dateng datan sinipi, amijang dakěn sang poetra, tiba ring padoekoeh, tamané Bibi Kilija, dané Tjili amanggih Rahadin déwi, noelija ing ngakenan. Poetri ikoe ija ingsoen niki, dan sang praboe Kling lawan Děhě, angrangkoel anaké agé, toewan Mantri kang den rangkoel, praméswari kalih angrangkoeli, kalih ingarasngaras, adoeh anak ingsoen, kaling anè sira mirah, poetra djati, paling mani nira ta nini, tan anjana sira gesang.

Poetoer manira anoelis, ring dina Boeda poenika, ring tanggal salikoer rěko, ing boelan Ramlan nika, marnaningsoen nanoerat, angen ingsoen sasar soesoer, tan aděrbé kadang warga. 